Check for updates

Cite this: Mater. Adv., 2021, 2, 728

Received 3rd September 2020, Accepted 27th November 2020

DOI: 10.1039/d0ma00677g

rsc.li/materials-advances

\title{
The design and synthesis of nonlinear optical chromophores containing two short chromophores for an enhanced electro-optic activity $\dagger$
}

\author{
Fenggang Liu, (D) *a Gangzhi Qin, ${ }^{a}$ Ziheng Li, ${ }^{a}$ Ziwei Wang, ${ }^{a}$ Meishan Peng, ${ }^{a}$ \\ Shuangke $\mathrm{Wu}^{a}{ }^{a}$ Chunlin $\mathrm{Li}^{\mathrm{a}}$ and Yuhui Yang (D)
}

\begin{abstract}
A series of nonlinear optical chromophores A-D based on the diethylaminophenyl donor and tricyanofuran or phenyl-trifluoromethyl-tricyanofuran acceptors coupled through a tetraene bridge was synthesized and investigated. In particular, the donor and bridge sections of chromophores B and D were functionalized with a small chromophore alkylaniline cyanoacetate (B1) and dialkylaminobenzylidene malononitrile (D1) group, respectively, compared to the pentafluorobenzene group of chromophores $\mathbf{A}$ and $\mathbf{C}$. Before poling, two small chromophores B1 and D1 with large dipole moment will greatly weaken the electrostatic interaction between chromophores by steric effect and electrostatic screening effect, thus increasing the poling efficiency. Although density functional theory calculations suggested that they have similar firstorder hyperpolarizability, polymeric thin films doped with chromophores A-D exhibited the different $r_{33}$ values of $115,166,213$ and $276 \mathrm{pm} \mathrm{V}^{-1}$ at $1310 \mathrm{~nm}$, respectively. The normalized $r_{33}$ value of chromphores $\mathbf{B}$ and $\mathbf{D}$ was up to $7.72 \times 10^{-19}$ and $17.25 \times 10^{-19} \mathrm{pm}$ cc per ( $\mathrm{V}$ molecules), which is much higher than that of chromophores $\mathbf{A}$ and $\mathbf{C}$. All these prove that introducing a small chromophore into the main chromophore can greatly improve the electro-optic coefficient of the chromophore by a rational molecular design.
\end{abstract}

\section{Introduction}

The information processes and transmission materials using photons as carriers have attracted extensive attention due to their advantages in transmission speed and bandwidth, as well as good parallelism, resistance to electromagnetic wave interference and high density. These materials have been widely used in optical communications and optical information processing, radar detection, optical switches and modulators. ${ }^{1-4}$ The key to the application of optoelectronic communication technology is whether electro-optical materials with excellent performance can be prepared. ${ }^{5}$ After years of development, the advantages of organic electro-optic materials have become increasingly apparent. ${ }^{6}$ Compared with inorganic materials (such as $\mathrm{LiNbO}_{3}$ and GaAs), organic electro-optic materials have high electro-optic coefficient, fast response speed, high

\footnotetext{
${ }^{a}$ School of Chemistry and Chemical Engineering, Guangzhou University, Guangzhou 510006, P. R. China. E-mail: liufg6@gzhu.edu.cn

${ }^{b}$ College of Materials Science and Engineering, Zhejiang Sci-Tech University, Hangzhou, 310018, P. R. China. E-mail: yhyang@zstu.edu.cn

$\dagger$ Electronic supplementary information (ESI) available. See DOI: 10.1039/ d0ma00677g
}

bandwidth, low dielectric constant, good processability and integration. ${ }^{7}$ In addition, organic materials can be easily integrated with semiconductor microelectronic devices, which have broad application prospects. ${ }^{8}$

The organic second-order nonlinear optical chromophore is the most important component of organic electro-optic materials. The chromophore is composed of donors, acceptors and bridges, usually with a large dipole moment. ${ }^{9}$ Many excellent chromophore molecules with large first-order hyperpolarizability were designed and synthesized. ${ }^{10}$ Among these, arylamine type donors, ${ }^{11,12}$ divinylthienyl (FTC), ${ }^{13}$ ring-locked tetraene (CLD) bridges, ${ }^{14}$ and tricyanofuran-based (TCF) $)^{15}$ or phenyl-trifluoromethyltricyanofuran $\left(\mathrm{CF}_{3}-\mathrm{Ph}-\mathrm{TCF}\right)$ acceptors ${ }^{16}$ were the most common and effective structure. A chromophore with large first-order hyperpolarizability is a necessary condition to obtain a large electro-optic coefficient. However, chromophores with large firstorder hyperpolarizability usually have large dipole moments. The electrostatic interaction between molecules will increase with an increase in the dipole moment. The dipole-dipole interaction between molecules will hinder the poling orientation of molecules in the electric field, thus reducing the polarization efficiency.

Hence, in the field of nonlinear optics, one major challenge is to effectively translate the hyperpolarizability $(\beta)$ values of the 
chromophore into high bulk EO activities. Introducing sterically hindered groups was usually an effective way to weaken the dipole moment between molecules, thereby increasing the electro-optic coefficient. Various isolation groups, such as silane, ${ }^{17}$ various aromatic structures ${ }^{18,19}$ and alkane ${ }^{20,21}$ were introduced to the different parts of chromophores to increase the electro-optic coefficient by steric effect. At the same time, other properties of the chromophore, such as the solvability, thermal stability and poling orientation stability were enhanced accordingly. ${ }^{22}$ Based on the isolation principle, many novel structures derived from steric groups have been designed, such as hyperbranched chromophorse, ${ }^{23}$ starshaped chromophores, ${ }^{24,25} \mathrm{H}$-shaped chromophores, ${ }^{26}$ multichromophore dendrimers ${ }^{27}$ and other dendritic chromophores ${ }^{28-30}$ in order to minimize unwanted electrostatic interactions.

Therefore, the following factors should be taken into consideration when selecting the steric groups: the first is the shape and size of the steric groups, which will affect the dipoledipole interaction between the chromophores. ${ }^{31}$ The second is that the rigidity of the steric group will affect the mobility of the molecule in the polarization process, while the steric group with too large volume and rigidity will hinder the polarization process. The last one is the molecular weight of the steric group. If the molecular weight is too large, the content of the active component chromosphere in the electro-optic film will be reduced. ${ }^{32}$

However, the traditional steric groups usually only play the role of isolation, and may reduce the chromophore content in the electro-optic films to a certain extent due to the large molecular weight. The chromophore with electro-optic activity was rarely used as the isolation group. ${ }^{5,33,34}$ Therefore, we designed new functional steric groups, alkylaniline cyanoacetate group (B1) and dialkylaminobenzylidene malononitriles (D1) group. They are not just steric groups, but also small chromophores with donor and acceptor. Although these two small chromophores do not have great first-order hyperpolarizability, their dipole moments $(\mu)$ cannot be ignored. In addition to the steric effect, the B1 and D1 groups with considerable $\mu$ will greatly weaken the electrostatic interaction between the molecules by electrostatic screening effect before poling, thus increasing the electro-optic coefficient. Four nonlinear optical chromophores A-D based on the same diethylaminophenyl donor and TCF or $\mathrm{CF}_{3}$-Ph-TCF acceptor coupled through the CLD bridge was synthesized and systematically investigated, as shown in Fig. 1. In particular, the donor and bridge moiety of chromophores $\mathbf{B}$ and D have been modified with B1 and D1 functional groups, respectively. In order to prove the advantages of the newly introduced functional groups, we also synthesized chromophores $\mathbf{A}$ and $\mathbf{C}$ with classic pentafluorophenyl isolation groups for comparison.

\section{Results and discussion}

\subsection{Synthesis and characterization of chromophores}

The synthetic route and details of chromophores A-D are presented in Fig. 2. The synthesis of chromophores A-D requires the following seven-step reaction, starting from the
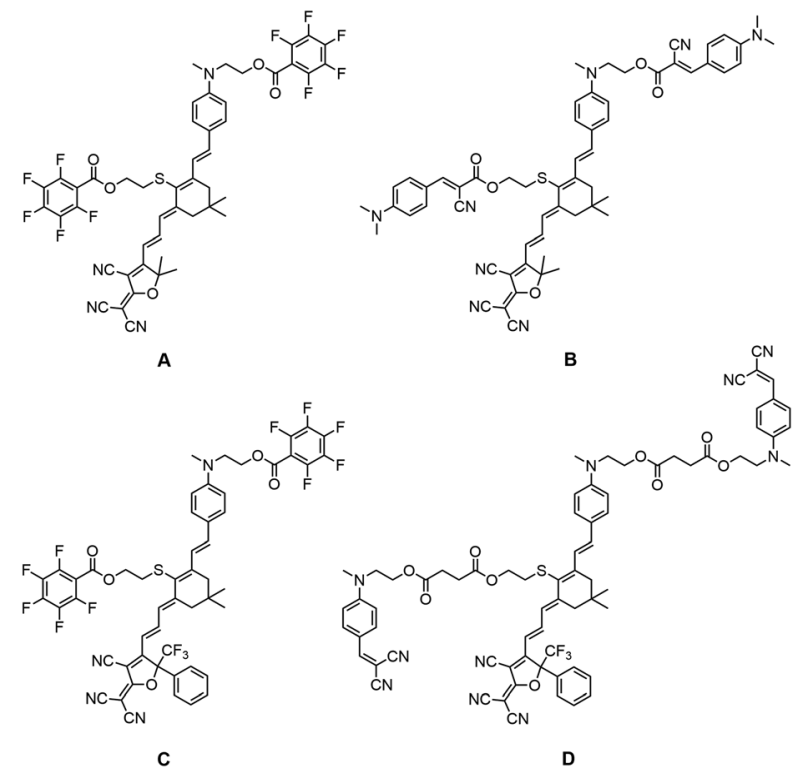

Fig. 1 Chemical structure for chromophores A-D.

diethylaminophenyl donor compounds 2: epoxy isophorone $\mathbf{1}$ was connected to donor 2 through Knoevenagel condensation, using sodium ethoxide as the base to yield compound 3 . Then, the tert-butyldimethylsilyl group was used to protect the hydroxyl group of compound 3 to afford compound 4 . Then, compound 4 was reacted with diethyl(cyanomethyl)phosphonate to give trienenitrile 5 by the Wittig-Horner reaction. Aldehyde 6 was obtained by reduction of the nitrile group of compound 5 . The TBDMS group on compound $\mathbf{6}$ was deprotected by the action of hydrochloric acid, and the hydroxyl group was yielded to facilitate the next step of compound 7. The aldehyde 8a-c was obtained by connecting the isolated group R1-R3 with the hydroxyl groups of compound 7 using the Steglich esterification. The final condensations with the tricyanovinyldihydrofuran (TCF) acceptor or phenyl-trifluoromethyl-tricyanofuran acceptors $\left(\mathrm{CF}_{3}-\mathrm{Ph}-\mathrm{TCF}\right)$ gave all four chromophores $\mathbf{A}-\mathbf{D}$ as green solids.

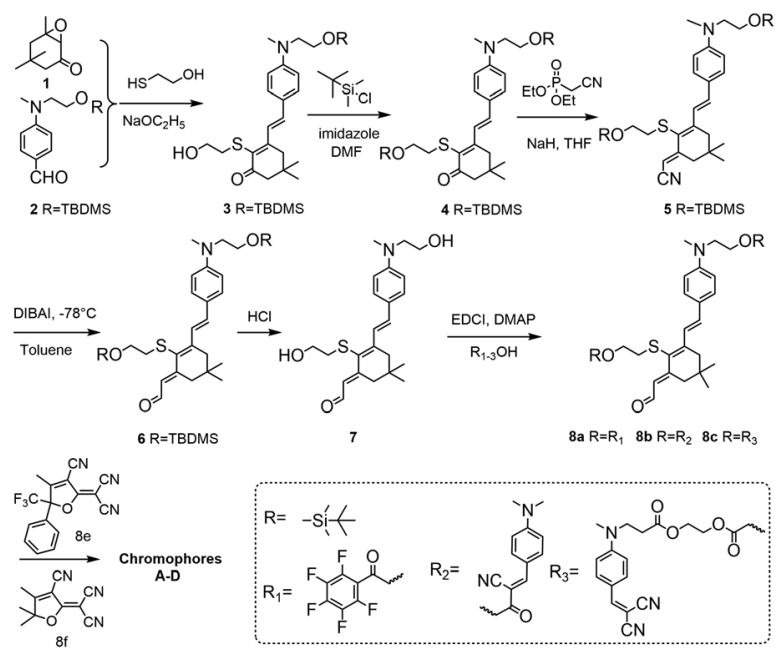

Fig. 2 Synthetic routes for chromophores A-D. 


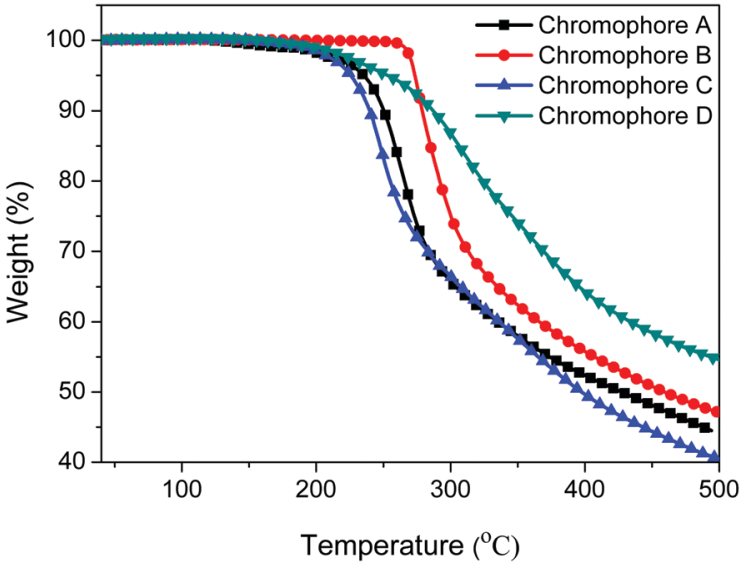

Fig. 3 TGA curves of chromophores A-D with a heating rate of $10^{\circ} \mathrm{C} \mathrm{min}-1$ under a nitrogen atmosphere.

The four chromophores were fully characterized by ${ }^{1} \mathrm{H}$ NMR and ${ }^{13} \mathrm{C}$ NMR and HRMS. The four chromophores possess good solubility in most common organic solvents, such as acetone, ethyl acetate and methylene chloride.

\subsection{Thermal stability}

The thermo gravimetric analysis (TGA) data were measured at a heating rate of $10{ }^{\circ} \mathrm{C} \mathrm{min}^{-1}$ under a nitrogen atmosphere to compare the thermal stability of the four chromophores. As shown in Fig. 3 and Table 1, the decomposition temperatures $\left(T_{\mathrm{d}}\right)$ of the four chromophores were higher than $220{ }^{\circ} \mathrm{C}(226-$ $273{ }^{\circ} \mathrm{C}$ ). Chromophore $\mathbf{B}$ has the highest decomposition temperature, followed by chromophore $\mathbf{D}$, chromophore $\mathbf{A}$ and chromophore C. All four chromophores were thermally stable to withstand the poling process and EO device applications. ${ }^{35}$

\subsection{Optical properties}

The UV-visible absorption spectra of the four chromophores A-D were measured in six kinds of solvents with different dielectric constants and in PMMA films in order to study the optical properties of the four chromophores. As shown in Fig. 4, 5, Fig. S1 (ESI $\dagger$ ) and Table 1, chromophores A, B, C and D show the maximum absorption $\left(\lambda_{\max }\right)$ values of $640 \mathrm{~nm}, 660 \mathrm{~nm}, 723 \mathrm{~nm}$ and $731 \mathrm{~nm}$ in chloroform, respectively. The $\lambda_{\max }$ values of chromophores B and D were both redshifted ( $c a$. 9-20 nm) compared to that of the unmodified chromophores $\mathbf{A}$ and $\mathbf{C}$ due to the electron withdrawing effect of the pentafluorobenzene group in chromophores $\mathbf{A}$ and $\mathbf{C} .^{35}$ Because of the stronger

Table 1 Thermal and optical properties data of the chromophores

\begin{tabular}{llllll}
\hline Cmpd & $T_{\mathrm{d}}\left({ }^{\circ} \mathrm{C}\right)$ & $\lambda_{\max }{ }^{a}$ & $\lambda_{\max }{ }^{b}$ & $\Delta \lambda^{c}$ & $\lambda_{\text {max }}{ }^{d}$ \\
\hline A & 235 & 640 & 601 & 39 & 624 \\
B & 273 & 660 & 627 & 33 & 665 \\
C & 226 & 723 & 663 & 60 & 732 \\
D & 253 & 731 & 673 & 58 & 792
\end{tabular}

${ }^{a} \lambda_{\max }(\mathrm{nm})$ values were measured in chloroform. ${ }^{b} \lambda_{\max }(\mathrm{nm})$ values were measured in dioxane. ${ }^{c} \Delta \lambda(\mathrm{nm})$ was the difference between ${ }^{a} \lambda_{\max }$ and ${ }^{b} \lambda_{\max }{ }^{d} \lambda_{\max }(\mathrm{nm})$ values were measured in film.

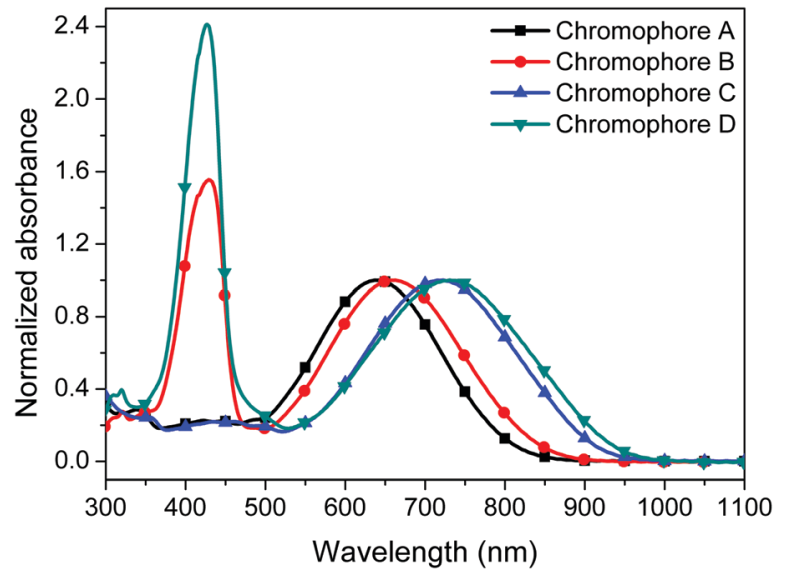

Fig. 4 UV-Vis absorption spectra of chromophores A-D in chloroform.

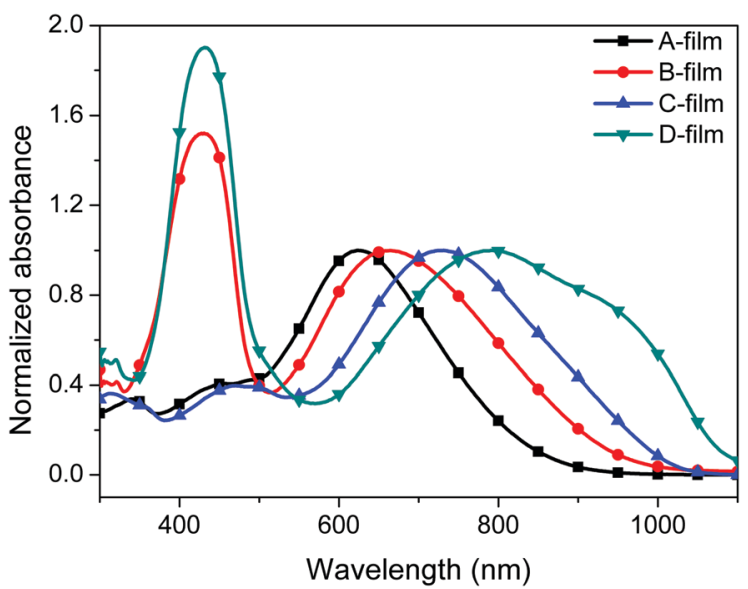

Fig. 5 UV-Vis absorption spectra of chromophores A-D in films.

acceptor $\mathrm{CF}_{3}-\mathrm{Ph}-\mathrm{TCF}$, chromophores $\mathbf{C}$ and $\mathbf{D}$ exhibited more red-shifted maximum absorption wavelengths in comparison with chromophores $\mathbf{A}$ and $\mathbf{B}$. For chromophores $\mathbf{B}$ and $\mathbf{D}$, another strong absorption band with a $\lambda_{\text {max }}$ in chloroform at $427 \mathrm{~nm}$ and $429 \mathrm{~nm}$ was from the two alkylaniline cyanoacetate and dialkylaminobenzylidene malononitriles groups, respectively.

We also tested the UV absorption of these chromophores in film. The absorption maxima $\left(\lambda_{\max }\right)$ of chromophores A-D in PMMA are $624 \mathrm{~nm}, 665 \mathrm{~nm}, 732 \mathrm{~nm}$ and $792 \mathrm{~nm}$, respectively. The absorption in the film was different from the absorption in chloroform. This was probably due to the different interactions between the chromophores and the polymers within different structures. It is also interesting to note that chromophores $\mathbf{B}$ and $\mathbf{D}$ differ much more strongly from those of chromophores $\mathbf{A}$ and $\mathbf{C}$, respectively, in the solid than in solution.

\subsection{Theoretical calculations}

The density functional theory (DFT) calculations were carried out using the Gaussian 09 program package at the R-B3LYP level by employing the split valence $6-31 \mathrm{~g}(\mathrm{~d})$ basis set to compare the dipole moment $(\mu)$, HOMO-LUMO energy gaps $\Delta E$ (DFT) 
Table 2 Summary of DFT and EO coefficients of chromophores

\begin{tabular}{llcrl}
\hline Cmpd & $\Delta E(\mathrm{DFT})^{a}(\mathrm{eV})$ & $\beta_{\text {tot }^{b}}\left(10^{-30} \mathrm{esu}\right)$ & $\mu^{c}(\mathrm{D})$ & $r_{33}{ }^{d}\left(\mathrm{pm} \mathrm{V}^{-1}\right)$ \\
\hline A & 2.293 & 904.5 & 20.82 & 115 \\
B & 2.202 & 1058.1 & 23.58 & 166 \\
C & 2.029 & 1085.2 & 22.69 & 213 \\
D & 2.009 & 1183.9 & 23.26 & 276 \\
B1 & 3.567 & 42.9 & 9.06 & - \\
D1 & 3.509 & 39.0 & 10.77 & -
\end{tabular}

${ }^{a}$ Calculated from DFT calculations. ${ }^{b}$ The first-order hyperpolarizability calculated from DFT calculations. ${ }^{c}$ The total dipole moment. ${ }^{d}$ At $30 \mathrm{wt} \%$.

and first hyperpolarizability $(\beta)$ of the four chromophores. ${ }^{36,37}$ All chromophores were assumed to be in trans-configuration. All of the calculated data are summarized in Table 2. Fig. S2 (ESI $\dagger$ ) describes the electron density distribution of the HOMO and LUMO structures of the chromophores. The density of the ground and excited state electron is asymmetric along the dipolar axis of the molecules.

The HOMO-LUMO energy gaps $\Delta E$ (DFT) of the four chromophores was calculated, as shown in Table 2. The trend of this data is consistent with the absorption of the UV absorption wavelength. In general, smaller energy differences between the molecules correlated with the redshift of the UV absorption wavelength.

The $\beta$ value of the four chromophores was also calculated using DFT calculations. The first hyperpolarizability of chromophore $\mathbf{C}$ with $\mathrm{CF}_{3}-\mathrm{Ph}-\mathrm{TCF}$ is larger than that of chromophore A due to the smaller energy gap caused by the stronger donor. ${ }^{38}$ In the same way, the first hyperpolarizability of compound $\mathbf{D}$ is greater than that of compound $\mathbf{B}$. The first hyperpolarizability of chromophore $\mathbf{A}$ is smaller than that of compound $\mathbf{B}$ with the same TCF acceptor due to the larger energy gap caused by the electron withdrawing effect of the pentafluorophenyl group.

Because the alkylaniline cyanoacetate group (B1) and dialkylaminobenzylidene malononitrile group (D1) can also be regarded as small chromophores, we calculated the first-order hyperpolarizability of these two functional groups. The calculated $\beta$ value of the B1 and D1 groups was $42.9 \times 10^{-30}$ esu and $39.0 \times 10^{-30}$ esu, respectively. These values were negligible relative to the first-order hyperpolarizability of the large chromophore $\left(\sim 1000 \times 10^{-30} \mathrm{esu}\right)$. Therefore, the introduction of these two functionalized groups does not have a large impact on the first-order hyperpolarizability of the chromophore. However, in terms of the dipole moment, the values of these small chromophores were worth mentioning. The dipole moments of B1 and D1 were 9.06 Debye and 10.77 Debye, respectively. This value cannot be ignored relative to the dipole moment of the large chromophore ( $\sim 20$ Debye). It should be noted that the dipole moments of the complex chromophores will depend on the conformation of the side chains.

\subsection{Electro-optic performance}

To test the effect of different functional groups on the electrooptic coefficient of the chromophores, electro-optic films with different doping concentrations were prepared. Different contents of chromophores were physically doped with polymer
PMMA, and then dibromoethane was added. To spin cast a chromophore film requires a solution of approximately $8-10 \mathrm{wt} \%$. After a night of stirring, the mixed solution was filtered through a $0.2 \mu \mathrm{m}$ PTFE filter and then spin-coated onto selected ITO glass. The prepared electro-optic film was dried in a vacuum drying oven overnight. The corona polarization process was carried out at 5-10 ${ }^{\circ} \mathrm{C}$ higher than the glass transition temperature $\left(T_{\mathrm{g}}\right)$ of the Electro-optic (EO) film. The electro-optic coefficients of the EO films were measured by Teng-Man simple reflection method, at the wavelength of $1310 \mathrm{~nm}$ using a carefully selected thin ITO electrode (resistivity $\leq 100 \mathrm{ohm} \mathrm{sq}^{-1}$ ). ${ }^{5,39}$

The electro-optic coefficient of the electro-optic film is usually related to the following parameters: the hyperpolarizability $(\beta)$ is the micro electro-optic coefficient of the chromophore molecule; the chromophore number density $(N)$ is the content of effective chromophore components in the electro-optic film. ${ }^{40}$ The poling efficiency means how many chromophore molecules are polarized and oriented. If the intermolecular dipole-dipole interaction can be ignored, the electro-optic coefficient will increase with $N, \beta$ of the chromophore and the poling efficiency. At low doping concentration, the electrostatic interaction between the chromophores is weak, so the $r_{33}$ value of the chromophore is mainly related to the chromophore number density and first-order hyperpolarizability of the chromophores. ${ }^{41,42}$ As the content of the chromophores in the electro-optic film gradually increases, the electrostatic interaction between the molecules cannot be ignored. Strong dipoledipole interactions between the molecules will hinder the polarization orientation of the molecules under the action of an electric field. So, although the chromophores have similar first-order hyperpolarizability, their macro electro-optic coefficients still differ greatly because of the difference in the steric hindrance groups.

In order to study the influence of the functionalized groups on the electro-optic coefficients of the chromophores, the doping of PMMA films with $10-40 \mathrm{wt} \%$ chromophores was prepared. We first tested the electro-optic coefficients of different chromophores at $10 \mathrm{wt} \%$ doping concentration. For the four chromophores, the poled films of A/PMMA, B/PMMA, C/PMMA and D/PMMA gave $r_{33}$ values of 46, 58, 84 and $95 \mathrm{pm} \mathrm{V}^{-1}$, respectively. The electro-optic coefficients of C/PMMA were larger than that of A/PMMA, and the electro-optic coefficients of D/PMMA were larger than that of B/PMMA, illustrating that the increased acceptor strength of the chromophores can increase their $r_{33}$ value due to the larger hyperpolarizability and better isolation effect. The electro-optic coefficients at higher doping concentrations were also measured, as shown in Fig. 6.

The electro-optic coefficients of film-A/PMMA gradually increased from $46 \mathrm{pm} \mathrm{V}^{-1}$ (at $10 \mathrm{wt} \%$ ) to $115 \mathrm{pm} \mathrm{V}^{-1}$ (at $30 \mathrm{wt} \%$ ) and dropped to $112 \mathrm{pm} \mathrm{V}^{-1}$ (at $35 \mathrm{wt} \%$ ). A similar trend was also observed for film-C/PMMA, whose $r_{33}$ values gradually increased from $84 \mathrm{pm} \mathrm{V}^{-1}$ (at $10 \mathrm{wt} \%$ ) to $213 \mathrm{pm} \mathrm{V}^{-1}$ (at $30 \mathrm{wt} \%$ ), and dropped to $212 \mathrm{pm} \mathrm{V}^{-1}$ (at $35 \mathrm{wt} \%$ ). However, the maximum $r_{33}$ value of chromophores $\mathbf{B}$ and $\mathbf{D}$ was obtained at higher doping concentration. The electro-optic coefficients of film-B/PMMA were gradually improved from $58 \mathrm{pm} \mathrm{V}^{-1}$ (10 wt\%) to $166 \mathrm{pm} \mathrm{V}^{-1}$ (35 wt \%), while the $r_{33}$ value dropped to $162 \mathrm{pm} \mathrm{V}^{-1}$ (40 wt\%). 


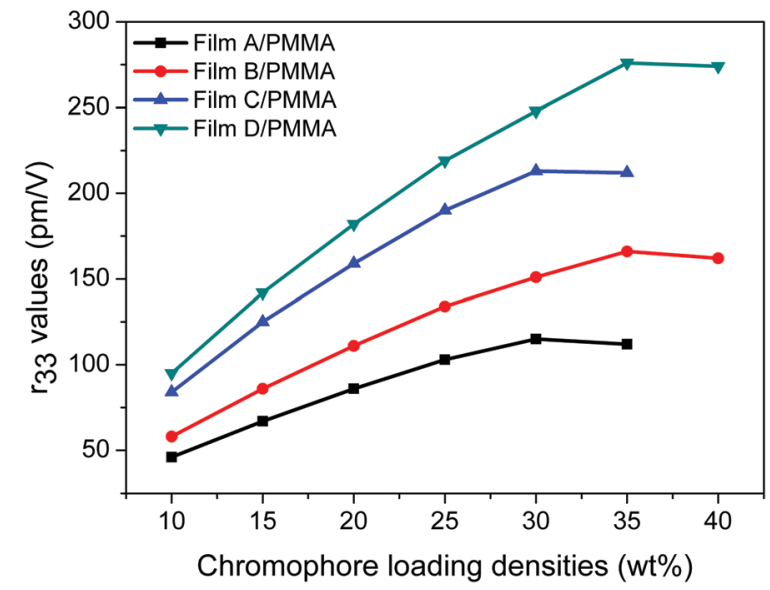

Fig. 6 The $r_{33}$ values of the NLO thin films as a function of the chromophore loading densities.

The electro-optic coefficients of film-B/PMMA were gradually improved from $95 \mathrm{pm} \mathrm{V}^{-1}$ (10 wt\%) to $276 \mathrm{pm} \mathrm{V}^{-1}$ (35 wt\%), while the $r_{33}$ value dropped to $274 \mathrm{pm} \mathrm{V}^{-1}$ (40 $\mathrm{wt} \%$ ).

The $\beta$ value of chromophores $\mathbf{B}$ and $\mathbf{D}$ are $48 \%$ and $9 \%$ higher than that of chromophores $\mathbf{A}$ and $\mathbf{C}$, respectively. Their $r_{33}$ values vary greatly, especially at high doping concentrations. At $10 \mathrm{wt} \%$ doping concentration, the electro-optic coefficients of chromophores $\mathbf{B}$ and $\mathbf{D}$ are $26 \%$ and $13 \%$ higher than that of chromophores $\mathbf{A}$ and $\mathbf{C}$, respectively. This is mainly due to the large first-order hyperpolarizabilities of chromophores $\mathbf{B}$ and $\mathbf{D}$. However, at $35 \mathrm{wt} \%$ doping concentration, the electro-optic coefficients of chromophores B and D are $48 \%$ and $30 \%$ higher than that of chromophores $\mathbf{A}$ and $\mathbf{C}$, respectively.

The number density of the chromophore will affect the $r_{33}$ value of the chromophore, so the number density of each chromophore at $30 \mathrm{wt} \%$ doping concentration was also calculated, as shown in Table 3. The chromophore number density of film A/PMMA, film B/PMMA, film C/PMMA and film D/PMMA is $2.17 \times 10^{20}, 2.15 \times 10^{20}, 1.94 \times 10^{20}$ and $1.60 \times$ $10^{20}$ molecules per $\mathrm{cm}^{3}$, respectively. By normalizing the electrooptic coefficients for the chromophore number density (at $35 \mathrm{wt} \%$ ): dividing the observed $r_{33}$ value by chromophore number density $(N)$, values of $5.16 \times 10^{-19} \mathrm{pm}$ cc per (V molecules), $7.72 \times$ $10^{-19} \mathrm{pm}$ cc per (V molecules), $10.93 \times 10^{-19} \mathrm{pm}$ cc per (V molecules) and $17.25 \times 10^{-19} \mathrm{pm}$ cc per (V molecules) were obtained for films A-D/PMMA, respectively.

With the increase of the doping concentration, the electrostatic interaction between the molecules becomes stronger and

Table 3 Representative $r_{33}$ values of the chromophores

\begin{tabular}{lllll}
\hline Chromophore & A & B & C & D \\
\hline$r_{33}\left(\mathrm{pm} \mathrm{V}^{-1}\right)$ & 112 & 166 & 212 & 276 \\
$N^{a}$ & 2.17 & 2.15 & 1.94 & 1.60 \\
$R_{33} / N^{b}$ & 5.16 & 7.72 & 10.93 & 17.25
\end{tabular}

${ }^{a}$ Chromophore number density at $35 \mathrm{wt} \%$; in units of $10^{20}$ molecules per $\mathrm{cm}^{3} .{ }^{b} r_{33}$ normalized by chromophore number density; in units of $10^{-19} \mathrm{pm}$ cc per (V molecules). stronger. The dipole-dipole interaction between the molecules will hinder the polarization orientation of the chromophores, so the introduction of steric groups can effectively improve the polarization efficiency and electro-optic coefficient. Pentafluorobenzene is a very effective isolating group. The $r_{33}$ value of the chromophore with a pentafluorobenzene isolating group was much larger than that for the chromophores without the isolating group. ${ }^{43}$

The dispersion enhancement, larger $\beta$ value and larger poling efficiency may be responsible for the greater $r_{33}$ values of chromophores $\mathbf{B}$ and $\mathbf{D}$ compared to chromophores $\mathbf{A}$ and $\mathbf{C}$. The isolation effect of the alkylaniline cyanoacetate group (B1) and dialkylaminobenzylidene malononitrile (D1) group should be similar to pentafluorobenzene, or even slightly weaker, because of the similar rigidity and size. However, the poling efficiency and electro-optic coefficient of chromophores $\mathbf{B}$ and $\mathbf{D}$ are much greater than those of chromophores $\mathbf{A}$ and $\mathbf{C}$ due to the functions of the B1 and D1 groups. Before poling, the chromophore molecules tend to be aligned in antiparallel orientation due to the electrostatic interactions between the molecules. Dipole-dipole interactions between the molecules will hinder the poling orientation of the molecules under an electric field. The overall dipole moment of chromophores $\mathbf{B}$ and $\mathbf{D}$ was lowered by the screening effect of the two B1 and D1 groups around the primary chromophores $\mathbf{B}$ and $\mathbf{D}$. The small chromophores B1 and D1 on the bridge and donor part of chromophores B and D will greatly weaken the electrostatic interaction between the molecules before the poling process. Then, the small chromophores B1 and D1 will be orientated under the action of an external electric field; thus, the dipole moment of chromophores $\mathbf{B}$ and $\mathbf{D}$ is enhanced. The process described above will greatly improve the polarization efficiency and electro-optic coefficient of chromophores $\mathbf{B}$ and $\mathbf{D}$. It should be mentioned that the $r_{33}$ value of film $\mathbf{B}$ and D/PMMA are very high compared to the EO films, which were doped with chromophores with the diethylaminophenyl donor and the TCF or $\mathrm{CF}_{3}$-Ph-TCF acceptor. ${ }^{11,35,44-46}$

\section{Conclusions}

In conclusion, we have developed and systematically investigated a series of nonlinear optical chromophores $\mathbf{A - C}$ based on the diethylaminophenyl donor and tricyanofuran or phenyltrifluoromethyl-tricyanofuran acceptors coupled through a tetraene bridge. The donor and bridge moiety of the chromophores $\mathbf{B}$ and $\mathbf{D}$ were functionalized with small chromophore alkylaniline cyanoacetate (B1) and dialkylaminobenzylidene malononitrile (D1) group, respectively. While the chromophores $\mathbf{A}$ and $\mathbf{C}$ were functionalized with the pentafluorobenzene group. In particular, the alkylaniline cyanoacetate and dialkylaminobenzylidene malononitrile groups were small chromophores with donor and acceptor. Before poling, two B1 and D1 groups with considerable dipole moment will greatly weaken the electrostatic interaction between the chromophores by electrostatic screening and steric effect. Then, the poling efficiency was increased with weakened 
dipole-dipole interaction. Although the DFT calculation suggests that the $\beta$ values of the four chromophores A-D were similar owing to their similar $\mathrm{D}-\pi-\mathrm{A}$ structure, the electro-optic coefficients of the four chromophores were quite different. As a result, the electro-optic films doped with chromophores A-D exhibited different $r_{33}$ values of 115, 166, 213 and $276 \mathrm{pm} \mathrm{V}^{-1}$ at $1310 \mathrm{~nm}$, respectively. The normalized $r_{33}$ values of chromphores $\mathbf{B}$ and $\mathbf{D}$ were up to $7.72 \times 10^{-19}$ and $17.25 \times 10^{-19} \mathrm{pm}$ cc per (V molecules), respectively, which is much higher than that of chromophores $\mathbf{A}$ and C without the small chromophore. This indicates that the small chromophores, alkylaniline cyanoacetate and dialkylaminobenzylidene malononitriles, introduced in the donor and bridge of the chromophores can improve the poling efficiency more effectively than the pentafluorobenzene group, thus greatly improving the $r_{33}$ value of the chromophores. In the meantime, the thermal decomposition temperature of the small chromophore-containing chromophores B and D was high than $250{ }^{\circ} \mathrm{C}$. The high thermal stability, together with the large electro-optic coefficient, suggests the potential use of these new chromophores in advanced electro-optic devices.

\section{Experimental}

\subsection{Materials and instrument}

All chemicals used were bought from chemical companies, and used directly without special purification. Methylene chloride (DCM), DMF and tetrahydrofuran (THF) were all commercial ultra-dry reagents (water $<50 \mathrm{ppm} \mathrm{L}^{-1}$ ). Compounds 2-7, chromophore $\mathbf{A}$ and chromophore $\mathbf{C}$ were synthesized according to literature. ${ }^{34}$ The NMR data $\left({ }^{1} \mathrm{H}\right.$ NMR and ${ }^{13} \mathrm{C}$ NMR) were measured on an Advance Bruker $500 \mathrm{M}(500 \mathrm{MHz}) \mathrm{NMR}$ spectrometer. The mass spectrometry data were tested on a MALDI-TOF (Matrix Assisted Laser Desorption/Ionization of Flight) instrument on a BIFLEXIII (Bruker, Inc.,) spectrometer. The TGA data were measured on a PerkinElmer TGA4000 with a heating rate of $10{ }^{\circ} \mathrm{C} \mathrm{min}^{-1}$ under nitrogen atmosphere. The UV-Vis spectra were collected on a Shimadzu UV1800 photospectrometer.

\subsection{Syntheses}

4.2.1 Synthesis of 2- $((4-)(E)-2-((E)-2-((2-)((E)-2-c y a n o-3-(4-$ (dimethylamino)phenyl)acryloyl)oxy)ethyl)thio)-5,5-dimethyl-3(2-oxoethylidene)cyclohex-1-en-1-yl)vinyl)phenyl)(methyl)amino)ethyl (Z)-3-cyano-4-(4-(dimethylamino)phenyl)but-3-enoate (compound 8b). EDCI (0.58 g, $3.00 \mathrm{mmol}),(E)$-2-cyano-3-(4-(dimethylamino)phenyl)acrylic acid (0.65 g, $3.00 \mathrm{mmol}), N, N$-dimethylaminopyridine $(0.037 \mathrm{~g}, 0.30 \mathrm{mmol})$ was dissolved in $20 \mathrm{~mL}$ dichloromethane under an argon atmosphere, and then cooled to $0{ }^{\circ} \mathrm{C}$. The mixture was cloudy at first. After the solution became clear, compound 7 $(0.40 \mathrm{~g}, 1.00 \mathrm{mmol})$ in $15 \mathrm{ml}$ of dichloromethane was added. The mixture continued to react for 2 hours at $0{ }^{\circ} \mathrm{C}$. The mixture was removed from the ice bath, and then heated to reflux overnight. After the reaction was complete, the mixture was then poured into water, extracted with $200 \mathrm{ml}$ dichloromethane, and concentrated with a rotary evaporator. The crude product was purified by silica gel chromatography column with ethyl acetate and petroleum ether $(\mathrm{v} / \mathrm{v}, 1: 8$ to $1: 5)$ as the eluent. The compound $\mathbf{8 b}$ was obtained as a red oil in 65\% yield (0.52 g, $0.65 \mathrm{mmol})$. MS (MALDI) $\left(\mathrm{M}^{+}\right.$, $\mathrm{C}_{47} \mathrm{H}_{51} \mathrm{~N}_{5} \mathrm{O}_{5} \mathrm{~S}$ ): calcd: 798.02; found: 798.14. ${ }^{1} \mathrm{H}$ NMR $(500 \mathrm{MHz}$, $\left.\mathrm{CDCl}_{3}\right) \delta 10.15(\mathrm{~d}, J=8.0 \mathrm{~Hz}, 1 \mathrm{H}, \mathrm{CHO}), 7.93(\mathrm{dd}, J=14.5,7.9 \mathrm{~Hz}$, $3 \mathrm{H}, \mathrm{CH}), 7.85$ (dd, $J=14.7,9.1 \mathrm{~Hz}, 4 \mathrm{H}, \mathrm{ArH}, \mathrm{CH}), 7.40$ (d, $J=8.9 \mathrm{~Hz}$, $2 \mathrm{H}, \mathrm{ArH}), 6.97$ (d, J=8.0 Hz, 1H, ArH), 6.83 (d, J=16.2 Hz, 1H, CH), 6.67-6.66 (m, 3H, ArH), 6.65-6.64 (m, 3H, ArH), 4.38 (t, $J=5.7 \mathrm{~Hz}$, $2 \mathrm{H}, \mathrm{NCH}_{2}$ ), 4.31 (t, $\left.J=6.5 \mathrm{~Hz}, 2 \mathrm{H}, \mathrm{OCH}_{2}\right), 3.67(\mathrm{t}, J=5.7 \mathrm{~Hz}, 2 \mathrm{H}$, $\mathrm{OCH}_{2}$ ), 3.09 (s, 6H, $\mathrm{NCH}_{3}$ ), 3.09 (s, 6H, $\left.\mathrm{NCH}_{3}\right), 3.02\left(\mathrm{~s}, 3 \mathrm{H}, \mathrm{NCH}_{3}\right.$ ), $2.90\left(\mathrm{t}, J=6.5 \mathrm{~Hz}, 2 \mathrm{H}, \mathrm{SCH}_{2}\right), 2.78\left(\mathrm{~s}, 2 \mathrm{H}, \mathrm{CH}_{2}\right), 2.51\left(\mathrm{~s}, 2 \mathrm{H}, \mathrm{CH}_{2}\right)$, $1.04\left(\mathrm{~s}, 6 \mathrm{H}, \mathrm{CH}_{3}\right) .{ }^{13} \mathrm{C} \mathrm{NMR}\left(126 \mathrm{MHz}, \mathrm{CDCl}_{3}\right) \delta$ 191.51, 164.27, $163.88,156.21,154.85,154.66,153.63,151.16,149.31,135.23$, $134.15,129.03,127.02,126.83,125.19,124.64,119.27,117.38$, 112.09, 111.43, 93.42, 93.03, 63.97, 62.93, 60.34, 50.70, 41.63, $39.97,38.85,30.08,28.31$.

4.2.2 Synthesis of 2-((4- $((E)-2-((E)-2-((2-)((E)-2-c y a n o-3-(4-$ (dimethylamino)phenyl)acryloyl)oxy)ethyl)thio)-3-((E)-3-(4-cyano5-(dicyanomethylene)-2,2-dimethyl-2,5-dihydrofuran-3-yl)allylidene)5,5-dimethylcyclohex-1-en-1-yl)vinyl)phenyl)(methyl)amino)ethyl( $Z$ )3-cyano-4-(4-(dimethylamino)phenyl)but-3-enoate (chromophore B). Acceptor TCF $(0.24 \mathrm{~g}, 1.20 \mathrm{mmol})$ and compound $\mathbf{8 b}(0.82 \mathrm{~g}$, $1.00 \mathrm{mmol}$ ) in $6 \mathrm{ml}$ dry ethanol and $4 \mathrm{ml}$ dry dichloromethane was added to a $100 \mathrm{ml}$ flask under argon atmosphere. The mixture reacted at $65{ }^{\circ} \mathrm{C}$ for 8 hours. Then, the organic solvent was concentrated using a rotary evaporator. The crude product was purified by silica gel chromatography column with dichloromethane/ethyl acetate (1:6 to $1: 4)$ as the eluent to afford chromophore $\mathbf{B}$ as a deep green solid in $68 \%$ yield $(0.67 \mathrm{~g}, 0.68 \mathrm{mmol})$. HRMS (ESI) $\left(\mathrm{M}^{+}, \mathrm{C}_{59} \mathrm{H}_{60} \mathrm{~N}_{8} \mathrm{O}_{5} \mathrm{~S}\right)$ : calcd: 993.4486; found: 993.4478. ${ }^{1} \mathrm{H}$ NMR (500 MHz, $\mathrm{CDCl}_{3}$ ) $\delta 8.17-8.12(\mathrm{~m}, 1 \mathrm{H}, \mathrm{ArH}), 7.98$ (d, $J=$ 8.7 Hz, 2H, ArH), 7.93-7.87 (m, 4H, CH, ArH), 7.57 (d, J=14.8 Hz, $1 \mathrm{H}, \mathrm{CH}), 7.45$ (d, $J=8.9 \mathrm{~Hz}, 2 \mathrm{H}, \operatorname{ArH}), 6.94(\mathrm{~d}, J=16.0 \mathrm{~Hz}, 1 \mathrm{H}$, $\mathrm{CH}), 6.75-6.65(\mathrm{~m}, 6 \mathrm{H}, \mathrm{ArH}), 6.46(\mathrm{~d}, J=14.8 \mathrm{~Hz}, 1 \mathrm{H}, \mathrm{CH}), 5.30$ $(\mathrm{s}, 1 \mathrm{H}, \mathrm{CH}), 4.43\left(\mathrm{t}, J=5.7 \mathrm{~Hz}, 2 \mathrm{H}, \mathrm{NCH}_{2}\right), 4.30(\mathrm{t}, J=5.9 \mathrm{~Hz}, 2 \mathrm{H}$, $\left.\mathrm{OCH}_{2}\right), 3.74\left(\mathrm{t}, J=5.7 \mathrm{~Hz}, 2 \mathrm{H}, \mathrm{OCH}_{2}\right), 3.14\left(\mathrm{~s}, 6 \mathrm{H}, \mathrm{NCH}_{3}\right), 3.10(\mathrm{~s}$, $\left.6 \mathrm{H}, \mathrm{NCH}_{3}\right), 3.09\left(\mathrm{~s}, 3 \mathrm{H}, \mathrm{NCH}_{3}\right), 2.96\left(\mathrm{t}, J=5.9 \mathrm{~Hz}, 2 \mathrm{H}, \mathrm{SCH}_{2}\right), 2.55$ $\left(\mathrm{s}, 2 \mathrm{H}, \mathrm{CH}_{2}\right), 2.52\left(\mathrm{~s}, 2 \mathrm{H}, \mathrm{CH}_{2}\right), 1.65\left(\mathrm{~s}, 3 \mathrm{H}, \mathrm{CH}_{3}\right), 1.60(\mathrm{~s}, 3 \mathrm{H}$, $\left.\mathrm{CH}_{3}\right), 1.03\left(\mathrm{~s}, 6 \mathrm{H}, \mathrm{CH}_{3}\right) .{ }^{13} \mathrm{C} \mathrm{NMR}\left(126 \mathrm{MHz}, \mathrm{CDCl}_{3}\right) \delta 176.27$, $173.55,164.32$, 164.02, 154.91, 154.45, 153.76, 151.92, 149.72, $144.81,136.49,134.26,129.42,128.75,128.12,125.29,124.83$, $119.20,117.48,117.21,112.55,112.21,111.92,111.57,97.18$, $94.22,93.02,63.42,62.89,55.17,53.39,50.80,41.78,41.11$, $40.01,39.03,34.26,30.34,28.36,26.17$.

4.2.3 Synthesis of 2-(((E)-2-((E)-4-((2-)(4-(2-)(4-(2,2-dicyanovinyl)phenyl)(methyl)amino)ethoxy)-4-oxobutanoyl)oxy)ethyl)(methyl)amino)styryl)-4,4-dimethyl-6-(2-oxoethylidene)cyclohex-1-en1-yl)thio)ethyl (2-((4-(2,2-dicyanovinyl)phenyl)(methyl)amino)ethyl) succinate (compound 8c). $N, N$-Dimethylaminopyridine (0.037 g, $0.30 \mathrm{mmol})$, EDCI $(0.58 \mathrm{~g}, 3.00 \mathrm{mmol})$ and $4-(2-((4-(2,2-$ dicyanovinyl)phenyl)(methyl)amino)ethoxy)-4-oxobutanoic acid (0.98 g, $3.00 \mathrm{mmol}$ ), was dissolved in $20 \mathrm{~mL}$ dichloromethane under an argon atmosphere, and then cooled to $0{ }^{\circ} \mathrm{C}$. The mixture was cloudy at first. After the solution became clear, compound $6(0.40 \mathrm{~g}, 1.00 \mathrm{mmol})$ in $15 \mathrm{ml}$ of dichloromethane was added. The mixture continued to react for 2 hours at $0{ }^{\circ} \mathrm{C}$. The mixture was removed from the ice bath, and then heated to reflux overnight. After the reaction was complete, the mixture was 
then poured into water, extracted with $200 \mathrm{ml}$ dichloromethane, and concentrated with a rotary evaporator. The crude product was purified by silica gel chromatography column with ethyl acetate and petroleum ether ( $\mathrm{v} / \mathrm{v}, 1: 8$ to $1: 5)$ as the eluent. The compound 8c was obtained as a red oil in 68\% yield (0.69 g, $0.68 \mathrm{mmol})$. MS (MALDI) $\left(\mathrm{M}^{+}, \mathrm{C}_{57} \mathrm{H}_{61} \mathrm{~N}_{7} \mathrm{O}_{9} \mathrm{~S}\right)$ : calcd: 1020.22; found: $1020.31 .{ }^{1} \mathrm{H}$ NMR $\left(500 \mathrm{MHz}, \mathrm{CDCl}_{3}\right) \delta 10.05$ (d, $J=8.1 \mathrm{~Hz}$, 1H, CHO), 7.84 (d, J=16.1 Hz, 1H, CH), 7.70-7.67 (m, 4H, CH, ArH), 7.36 (d, $J=8.9 \mathrm{~Hz}, 2 \mathrm{H}, \mathrm{ArH}), 7.34$ (d, $J=2.6 \mathrm{~Hz}, 2 \mathrm{H}, \mathrm{ArH}), 6.89-6.77$ (m, 2H, CH), 6.69-6.56 (m, 6H, ArH), 4.23-4.18 (m, 6H, $\mathrm{NCH}_{2}$ ), 4.03 $\left(\mathrm{t}, J=7.1 \mathrm{~Hz}, 4 \mathrm{H}, \mathrm{OCH}_{2}\right), 3.66-3.62\left(\mathrm{~m}, 4 \mathrm{H}, \mathrm{OCH}_{2}\right), 3.55(\mathrm{t}, J=5.8 \mathrm{~Hz}$, $\left.2 \mathrm{H}, \mathrm{OCH}_{2}\right), 3.04\left(\mathrm{~s}, 3 \mathrm{H}, \mathrm{NCH}_{3}\right), 3.03\left(\mathrm{~s}, 3 \mathrm{H}, \mathrm{NCH}_{3}\right), 2.94(\mathrm{~s}, 3 \mathrm{H}$, $\left.\mathrm{NCH}_{3}\right), 2.76-2.69\left(\mathrm{~m}, 2 \mathrm{H}, \mathrm{OCH}_{2}\right), 2.67-2.65\left(\mathrm{~m}, 2 \mathrm{H}, \mathrm{SCH}_{2}\right), 2.50-$ 2.47 (m, 4H, $\left.\mathrm{SCH}_{2}, \mathrm{OCH}_{2}\right), 2.10(\mathrm{~s}, 2 \mathrm{H}, \mathrm{CH} 2), 1.95\left(\mathrm{~s}, 2 \mathrm{H}, \mathrm{CH}_{2}\right), 0.97$ $\left(\mathrm{s}, 6 \mathrm{H}, \mathrm{CH}_{3}\right) .{ }^{13} \mathrm{C} \mathrm{NMR}\left(126 \mathrm{MHz}, \mathrm{CDCl}_{3}\right) \delta 190.99,171.59,171.38$, $170.55,157.63,155.97,153.15,150.63,149.16,134.86,133.41$, $128.55,126.78,126.39,124.73,124.28,119.28,115.47,114.45$, $111.68,111.40,71.68,62.54,61.31,60.93,59.89,50.23,41.21$, $38.50,38.27,33.10,29.57,28.69,27.83$.

4.2.4 Synthesis of 2- $((4-)(E)-2-((E)-2-((2-)((E)-2-c y a n o-3-(4-$ (dimethylamino)phenyl)acryloyl)oxy)ethyl)thio)-3-((E)-3-(4-cyano5-(dicyanomethylene)-2,2-dimethyl-2,5-dihydrofuran-3-yl)allylidene)5,5-dimethylcyclohex-1-en-1-yl)vinyl)phenyl)(methyl)amino) ethyl( $Z$ )-3-cyano-4-(4-(dimethylamino)phenyl)but-3-enoate (chromophore D). Acceptor $\mathrm{CF}_{3}-\mathrm{Ph}-\mathrm{TCF}(0.38 \mathrm{~g}, 1.20 \mathrm{mmol})$ and compound $8 \mathrm{c}(1.00 \mathrm{~g}, 1.00 \mathrm{mmol})$ in $6 \mathrm{ml}$ dry ethanol and $4 \mathrm{ml}$ dry dichloromethane were added to a $100 \mathrm{ml}$ flask under argon atmosphere. The mixture reacted at $65{ }^{\circ} \mathrm{C}$ for 8 hours. Then, the organic solvent was concentrated using a rotary evaporator. The crude product was purified by silica gel chromatography column with dichloromethane/ethyl acetate (1:6 to $1: 4)$ as the eluent to afford chromophore $\mathrm{D}$ as a deep green solid in $71 \%$ yield $(0.93 \mathrm{~g}$, $0.71 \mathrm{mmol})$. HRMS (ESI) $\left(\mathrm{M}^{+}, \mathrm{C}_{73} \mathrm{H}_{67} \mathrm{~F}_{3} \mathrm{~N}_{10} \mathrm{O}_{9} \mathrm{~S}\right)$ : calcd: 1317.4844; found: $1317.4813 .{ }^{1} \mathrm{H}$ NMR $\left(500 \mathrm{MHz}, \mathrm{CDCl}_{3}\right) \delta 7.95(\mathrm{~d}, J=15.9 \mathrm{~Hz}$, 1H, CH), 7.81-7.72 (m, 4H, ArH), 7.59-7.48 (m, 4H, CH), 7.46-7.38 (m, 5H, ArH), 7.00 (d, J = 15.9 Hz, 1H, CH), 6.75-6.66 (m, 8H, ArH), $6.56(\mathrm{~d}, J=14.6 \mathrm{~Hz}, 1 \mathrm{H}, \mathrm{CH}), 4.30-4.25$ (m, 8H, $\left.\mathrm{NCH}_{2}, \mathrm{OCH}_{2}\right), 4.14-$ $4.06\left(\mathrm{~m}, 4 \mathrm{H}, \mathrm{OCH}_{2}\right), 3.70\left(\mathrm{q}, J=5.9 \mathrm{~Hz}, 4 \mathrm{H}, \mathrm{OCH}_{2}\right), 3.64(\mathrm{t}, J=5.9 \mathrm{~Hz}$, $\left.2 \mathrm{H}, \mathrm{OCH}_{2}\right), 3.11\left(\mathrm{~s}, 3 \mathrm{H}, \mathrm{NCH}_{3}\right), 3.09\left(\mathrm{~s}, 3 \mathrm{H}, \mathrm{NCH}_{3}\right), 3.04\left(\mathrm{~s}, 3 \mathrm{H}, \mathrm{NCH}_{3}\right)$, $2.77\left(\mathrm{t}, J=6.5 \mathrm{~Hz}, 2 \mathrm{H}, \mathrm{SCH}_{2}\right), 2.58-2.54\left(\mathrm{~m}, 4 \mathrm{H}, \mathrm{OCH}_{2}\right), 2.28$ (s, 2H, $\mathrm{CH}_{2}$ ), 2.03 (s, 2H, $\mathrm{CH}_{2}$ ), 0.97 (s, 3H, $\left.\mathrm{CH}_{3}\right), 0.87$ (s, 3H, $\mathrm{CH}_{3}$ ). ${ }^{13} \mathrm{C} \mathrm{NMR}\left(126 \mathrm{MHz}, \mathrm{CDCl}_{3}\right) \delta 174.51,171.05,170.76,170.09,161.91$, 157.05, 156.39, 153.30, 152.53, 149.25, 146.40, 137.02, 132.81, 130.43, 129.10, 128.43, 127.94, 127.44, 125.83, 124.16, 123.79, 118.80, 116.39, 114.76, 113.73, 111.18, 110.82, 110.22, 109.73, 95.58, 95.20, 94.95, $71.68,61.98,60.67,60.32,59.36,57.10,49.66,40.75,40.11,38.87,37.85$, $33.19,32.51,29.35,29.05,27.79,27.58,27.29,26.78,20.03,13.20$.

\section{Conflicts of interest}

There are no conflicts to declare.

\section{Acknowledgements}

We gratefully acknowledge the National Natural Science Foundation of China (No. 21805049) and Guangzhou Municipal
Science and Technology Project (No. 201904010176) for the financial support.

\section{Notes and references}

1 Y. A. Getmanenko, T. G. Allen, H. Kim, J. M. Hales, B. Sandhu, M. S. Fonari, K. Y. Suponitsky, Y. Zhang, V. N. Khrustalev, J. D. Matichak, T. V. Timofeeva, S. Barlow, S.-H. Chi, J. W. Perry and S. R. Marder, Adv. Funct. Mater., 2018, 28, 1804073.

2 J. Luo, X.-H. Zhou and A. K. Y. Jen, J. Mater. Chem., 2009, 19, 7410-7424.

3 W. Heni, Y. Kutuvantavida, C. Haffner, H. Zwickel, C. Kieninger, S. Wolf, M. Lauermann, Y. Fedoryshyn, A. F. Tillack, L. E. Johnson, D. L. Elder, B. H. Robinson, W. Freude, C. Koos, J. Leuthold and L. R. Dalton, ACS Photonics, 2017, 4, 1576-1590.

4 M. Ayata, Y. Fedoryshyn, W. Heni, B. Baeuerle, A. Josten, M. Zahner, U. Koch, Y. Salamin, C. Hoessbacher, C. Haffner, D. L. Elder, L. R. Dalton and J. Leuthold, Science, 2017, 358, 630-632.

5 D. L. Elder, C. Haffner, W. Heni, Y. Fedoryshyn, K. E. Garrett, L. E. Johnson, R. A. Campbell, J. D. Avila, B. H. Robinson, J. Leuthold and L. R. Dalton, Chem. Mater., 2017, 29, 6457-6471.

6 H. Xu, F. Liu, D. L. Elder, L. E. Johnson, Y. de Coene, K. Clays, B. H. Robinson and L. R. Dalton, Chem. Mater., 2020, 32, 1408-1421.

7 P. A. Sullivan and L. R. Dalton, Acc. Chem. Res., 2010, 43, 10-18. 8 L. R. Dalton, P. A. Sullivan and D. H. Bale, Chem. Rev., 2010, 110, 25-55.

9 Z. Li, Q. Li and J. Qin, Polym. Chem., 2011, 2, 2723-2740.

10 S. Pascal, Y. A. Getmanenko, Y. Zhang, I. Davydenko, N. Minh Hoang, G. Pilet, S. Redon, Y. Bretonniere, O. Maury, I. Ledoux-Rak, S. Barlow, S. R. Marder and C. Andraud, Chem. Mater., 2018, 30, 3410-3418.

11 Y.-J. Cheng, J. Luo, S. Huang, X. Zhou, Z. Shi, T.-D. Kim, D. H. Bale, S. Takahashi, A. Yick, B. M. Polishak, S.-H. Jang, L. R. Dalton, P. J. Reid, W. H. Steier and A. K. Y. Jen, Chem. Mater., 2008, 20, 5047-5054.

12 O. Kwon, S. Barlow, S. A. Odom, L. Beverina, N. J. Thompson, E. Zojer, J. L. Bredas and S. R. Marder, J. Phys. Chem. A, 2005, 109, 9346-9352.

13 Y. Yang, H. Xu, F. Liu, H. Wang, G. Deng, P. Si, H. Huang, S. Bo, J. Liu, L. Qiu, Z. Zhen and X. Liu, J. Mater. Chem. C, 2014, 2, 5124-5132.

14 D. Briers, L. De Cremer, G. Koeckelberghs, S. Foerier, T. Verbiest and C. Samyn, Macromol. Rapid Commun., 2007, 28, 942-947.

15 M. Q. He, T. M. Leslie and J. A. Sinicropi, Chem. Mater., 2002, 14, 2393-2400.

16 S. Liu, M. A. Haller, H. Ma, L. R. Dalton, S. H. Jang and A. K. Y. Jen, Adv. Mater., 2003, 15, 603-607.

17 Y. Yang, J. Liu, M. Zhang, F. Liu, H. Wang, S. Bo, Z. Zhen, L. Qiu and X. Liu, J. Mater. Chem. C, 2015, 3, 3913-3921. 
18 J. D. Luo, Y. J. Cheng, T. D. Kim, S. Hau, S. H. Jang, Z. W. Shi, X. H. Zhou and A. K. Y. Jen, Org. Lett., 2006, 8, 1387-1390.

19 S. R. Hammond, O. Clot, K. A. Firestone, D. H. Bale, D. Lao, M. Haller, G. D. Phelan, B. Carlson, A. K. Y. Jen, P. J. Reid and L. R. Dalton, Chem. Mater., 2008, 20, 3425-3434.

20 X. Zhang, I. Aoki, X. Piao, S. Inoue, H. Tazawa, S. Yokoyama and A. Otomo, Tetrahedron Lett., 2010, 51, 5873-5876.

21 Y. Yang, S. Bo, H. Wang, F. Liu, J. Liu, L. Qiu, Z. Zhen and X. Liu, Dyes Pigm., 2015, 122, 139-146.

22 F. Liu, M. Zhang, H. Xiao, Y. Yang, H. Wang, J. Liu, S. Bo, Z. Zhen, X. Liu and L. Qiu, J. Mater. Chem. C, 2015, 3, 9283-9291.

23 Y. W. Bai, N. H. Song, J. P. Gao, X. Sun, X. M. Wang, G. M. Yu and Z. Y. Wang, J. Am. Chem. Soc., 2005, 127, 2060-2061.

24 P. Gopalan, H. E. Katz, D. J. McGee, C. Erben, T. Zielinski, D. Bousquet, D. Muller, J. Grazul and Y. Olsson, J. Am. Chem. Soc., 2004, 126, 1741-1747.

25 Z. a. Li, P. Chen, Y. Xie, Z. Li and J. Qin, Adv. Electron. Mater., 2017, 3, 1700138.

26 H. Xu, F. Liu, S. Chen, W. Shi, Z. Xie, J. Wang, Z. Zhai, J. Liu, H. Li and J. Wang, Dyes Pigm., 2019, 165, 144-150.

27 P. A. Sullivan, H. Rommel, Y. Liao, B. C. Olbricht, A. J. P. Akelaitis, K. A. Firestone, J.-W. Kang, J. Luo, J. A. Davies, D. H. Choi, B. E. Eichinger, P. J. Reid, A. Chen, A. K. Y. Jen, B. H. Robinson and L. R. Dalton, J. Am. Chem. Soc., 2007, 129, 7523-7530.

28 G. Liu, Q. Liao, H. Deng, W. Zhao, P. Chen, R. Tang, Q. Li and Z. Li, J. Mater. Chem. C, 2019, 7, 7344-7351.

29 X. Zang, G. Liu, Q. Li, Z. A. Li and Z. Li, Macromolecules, 2020, 53, 4012-4021.

30 H. Xu, J. Liu, J. Liu, C. Yu, Z. Zhai, G. Qina and F. Liu, Mater. Chem. Front., 2020, 4, 168-175.

31 J. Wu, C. Peng, H. Xiao, S. Bo, L. Qiu, Z. Zhen and X. Liu, Dyes Pigm., 2014, 104, 15-23.

32 H. Ma, S. Liu, J. D. Luo, S. Suresh, L. Liu, S. H. Kang, M. Haller, T. Sassa, L. R. Dalton and A. K. Y. Jen, Adv. Funct. Mater., 2002, 12, 565-574.

33 W. Jin, P. V. Johnston, D. L. Elder, K. T. Manner, K. E. Garrett, W. Kaminsky, R. Xu, B. H. Robinson and L. R. Dalton, J. Mater. Chem. C, 2016, 4, 3119-3124.

34 J. Lei, C. Guo, F. Liu, S. Chen, W.-J. Shi, Z. Wang, Z. Zhai, S. Mo and J. Wang, Dyes Pigm., 2019, 170, 107607.

35 F. Liu, S. Chen, S. Mo, G. Qin, C. Yu, W. Zhang, W.-J. Shi, P. Chen, H. Xu and M. Fu, J. Mater. Chem. C, 2019, 7, 8019-8028.
36 M. J. Frisch, G. W. Trucks, H. B. Schlegel, G. E. Scuseria, M. A. Robb, J. R. Cheeseman, G. Scalmani, V. Barone, B. Mennucci, G. A. Petersson, H. Nakatsuji, M. Caricato, X. Li, H. P. Hratchian, A. F. Izmaylov, J. Bloino, G. Zheng, J. L. Sonnenberg, M. Hada, M. Ehara, K. Toyota, R. Fukuda, J. Hasegawa, M. Ishida, T. Nakajima, Y. Honda, O. Kitao, H. Nakai, T. Vreven, J. A. Montgomery Jr., J. E. Peralta, F. Ogliaro, M. J. Bearpark, J. Heyd, E. N. Brothers, K. N. Kudin, V. N. Staroverov, R. Kobayashi, J. Normand, K. Raghavachari, A. P. Rendell, J. C. Burant, S. S. Iyengar, J. Tomasi, M. Cossi, N. Rega, N. J. Millam, M. Klene, J. E. Knox, J. B. Cross, V. Bakken, C. Adamo, J. Jaramillo, R. Gomperts, R. E. Stratmann, O. Yazyev, A. J. Austin, R. Cammi, C. Pomelli, J. W. Ochterski, R. L. Martin, K. Morokuma, V. G. Zakrzewski, G. A. Voth, P. Salvador, J. J. Dannenberg, S. Dapprich, A. D. Daniels, Ö. Farkas, J. B. Foresman, J. V. Ortiz, J. Cioslowski and D. J. Fox, Gaussian 09, 2009.

37 I. Davydenko, S. Benis, S. B. Shiring, J. Simon, R. Sharma,

T. G. Allen, S.-H. Chi, Q. Zhang, Y. A. Getmanenko, T. C. Parker, J. W. Perry, J.-L. Bredas, D. J. Hagan, E. W. Van Stryland, S. Barlow and S. R. Marder, J. Mater. Chem. C, 2018, 6, 3613-3620.

38 F. Liu, H. Zhang, H. Xiao, H. Xu, S. Bo, L. Qiu, Z. Zhen, L. Lai, S. Chen and J. Wang, Dyes Pigm., 2018, 157, 55-63.

39 L. R. Dalton, P. A. Sullivan, D. H. Bale and B. C. Bricht, SolidState Electron., 2007, 51, 1263-1277.

40 L. R. Dalton, D. Lao, B. C. Olbricht, S. Benight, D. H. Bale, J. A. Davies, T. Ewy, S. R. Hammond and P. A. Sullivan, Opt. Mater., 2010, 32, 658-668.

41 J. Wu, Q. Li, W. Wang, G. Deng, X. Zhang, Z. Li, H. Xiao and J. Liu, Mater. Lett., 2017, 199, 72-74.

42 H. Zhang, H. Xiao, F. Liu, F. Huo, Y. He, Z. Chen, X. Liu, S. Bo, L. Qiu and Z. Zhen, J. Mater. Chem. C, 2017, 5, 1675-1684.

43 J. D. Luo, H. Ma, M. Haller, A. K. Y. Jen and R. R. Barto, Chem. Commun., 2002, 888-889.

44 C. Zhang, C. G. Wang, J. L. Yang, L. R. Dalton, G. L. Sun, H. Zhang and W. H. Steier, Macromolecules, 2001, 34, 235-243.

45 X.-H. Zhou, J. Davies, S. Huang, J. Luo, Z. Shi, B. Polishak, Y.-J. Cheng, T.-D. Kim, L. Johnson and A. Jen, J. Mater. Chem., 2011, 21, 4437-4444.

46 X.-H. Zhou, J. Luo, J. A. Davies, S. Huang and A. K. Y. Jen, J. Mater. Chem., 2012, 22, 16390-16398. 